\title{
Combined per-capita and abundance effects of an invasive species on native invertebrate diversity and a key ecosystem process
}

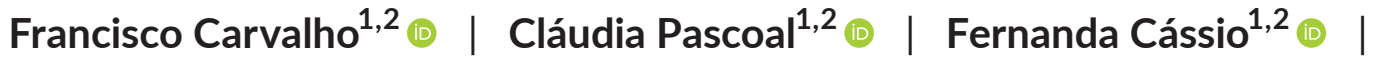 \\ Amílcar Teixeira $^{3}$ ( ) | Ronaldo Sousa ${ }^{1,2}$ (1)
}

${ }^{1}$ Biology Department, CBMA- Center of Molecular and Environmental Biology, University of Minho, Braga, Portugal

${ }^{2}$ IB-S- Institute of Science and Innovation for Bio-Sustainability, University of Minho, Braga, Portugal

${ }^{3}$ Centro de Investigação de Montanha (CIMO), Instituto Politécnico de Bragança, Bragança, Portugal

Correspondence

Francisco Carvalho, CBMA - Center of Molecular and Environmental Biology, Biology Department, University of Minho, Braga, Portugal.

Emails: fcarvalho@bio.uminho.pt; franciscocarvalhobio@gmail.com

Funding information

This work was supported by the strategic programme UIDB/04050/2020 funded by the Portuguese Foundation for Science and Technology (FCT). FCT supported this work through the scholarship SFRH/ BD/119957/2016 (F. Carvalho).

\section{Abstract}

1. Invasive alien species (IAS) are leading to the homogenisation of taxonomic and functional biodiversity, with negative consequences for key ecosystem processes in fresh water. Invasive signal crayfish (Pacifastacus leniusculus) is expected to disrupt detritus-based food webs by affecting leaf breakdown and/or by decreasing invertebrate density and diversity through predation. The combination of per-capita and abundance effects of $P$. leniusculus in invaded ecosystems is still largely unknown.

2. A four-week field experiment was established in Rabaçal and Tuela Rivers (NE Portugal) to assess effects of $P$. leniusculus on invertebrate taxonomic and functional diversity and leaf litter breakdown following a gradient of invasion. We controlled the presence and absence of crayfish by placing the animals and leaf litter inside cages at six sites (three sites per river) according to the crayfish in situ abundance (absent, low, high). Cages were covered with coarse- or finemesh net to allow or prevent invertebrates from accessing the leaves.

3. Results showed that higher crayfish in situ abundance led to a decrease in abundance, richness and Shannon diversity of invertebrates and to changes in the communities' structures. Higher crayfish abundance led also to a decrease in invertebrate functional redundancy and an increase in the percentage of invertebrate taxa with resistance forms. Leaf litter breakdown increased with crayfish presence and decreased at sites with higher crayfish abundance.

4. Overall, signal crayfish changed the community structure of invertebrates, with potential severe long-term effects on native communities and leaf litter breakdown. Given the widespread distribution of signal crayfish (and other crayfish species), their ecological impacts should be assessed carefully, especially in pristine freshwater ecosystems such as those described here.

KEYWORDS

functional diversity, leaf litter breakdown, signal crayfish, streams, taxonomic diversity 


\section{1 | INTRODUCTION}

Global freshwater diversity is facing an unprecedented crisis driven by direct and indirect anthropogenic influence (Dawson, 2012; Dudgeon et al., 2006; Strayer, 2006; Tickner et al., 2020). The introduction of invasive alien species (IAS), in conjunction with habitat loss and fragmentation, climate change, pollution and resource overexploitation, is contributing to species declines or, in extreme cases, even extinction (Dudgeon et al., 2006; Pyšek et al., 2020; Reid et al., 2019). The introduction of IAS may cause significant changes in native biodiversity and ecosystem processes by altering biotic interactions (e.g., carrying novel diseases and parasites, competing for space and resources, changing predator-prey interactions), physically altering the habitat (ecosystem engineering) or changing assimilatory-dissimilatory (uptake and release of energy and materials) interactions (Carpenter et al., 2011; Gallardo et al., 2016; Gutiérrez et al., 2014; Simberloff et al., 2013; Sousa et al., 2009). By interfering with native species and ecosystem processes, IAS are leading to taxonomic (Olden, 2006) and functional (Olden et al., 2004) global homogenisation of biota, decreasing their resistance and resilience to new disturbances (Clavel et al., 2011; Downing et al., 2012).

The impacts of IAS may vary spatially and temporally depending on important factors, such as population density (Benkwitt, 2015; Pintor et al., 2009), phenotypic diversity (Carvalho et al., 2018), propagule pressure (Barney et al., 2016; Warren et al., 2012), functional distinctiveness (Ehrenfeld, 2010; Sousa et al., 2011) and environmental characteristics of the invaded area (Strayer et al., 2006). However, the invasion process (e.g., establishment, population growth, dispersion or niche occupation) may be context-dependent and perhaps change through time as a consequence of evolutionary responses by native species, increasing the unpredictability of IAS impacts (Buckley, 2017; Mooney \& Cleland, 2001). Given the degree of uncertainty in assessing IAS effects (e.g., Jarić et al., 2019), scientists have been trying to develop strategies to implement comparable approaches to better predict their ecological impacts (Bacher et al., 2018; Blackburn et al., 2014; Kumschick et al., 2015; Thomsen et al., 2011).

Freshwater crayfish species are amongst the most widespread (Marean, 2015; Vilà et al., 2009) and problematic IAS as a result of their potential ecological and economic impacts (Twardochleb et al., 2013). The omnivorous behaviour of invasive crayfish may be responsible for impacts at different trophic levels through alterations of key ecosystem functions (nutrient cycling, primary and secondary production) and/or direct consumption of plant litter, invertebrates and/or other taxonomic groups (e.g., Carvalho et al., 2016). In fresh water, the breakdown of allochthonous organic matter is a key ecosystem process mediated by microorganisms and aquatic invertebrates that ensures energy flow and nutrient cycling (Covich et al., 1999; Graça, 2001; Tiegs et al., 2019; Tolkkinen et al., 2020). Allochthonous organic matter breakdown is affected by abiotic (e.g., eutrophication, Gulis et al., 2006; Dunck et al., 2015; Pereira et al., 2016; pesticides, Pimentão et al., 2020) and biotic (e.g., predation, Atwood et al., 2013) factors, which affects the diversity of native invertebrate detritivores.

Omnivores, as crayfish, may play an important role in food web dynamics by increasing or decreasing stability through competition or predation (Wootton, 2017). Some studies also demonstrated that IAS can compensate for native biodiversity loss by functional replacement (Zwerschke et al., 2020) and guarantee important ecosystem functions. In addition, the mechanisms explaining the dynamic between the increase in population density and the effects of IAS along the invasion process are still a matter of debate. Impacts of IAS are expected to be higher with increasing abundances above a certain threshold, but organisms may exhibit niche plasticity and change their niche dimension and effects through time (Havel et al., 2015; Jackson et al., 2015). Per-capita effects may change as the abundance of IAS increases, consequently reducing the availability of native preys with depletion of resources. Simultaneously, native prey may develop evolutionary mechanisms of defence to avoid or reduce predation pressures by IAS, including against invasive crustaceans (Freeman \& Byers, 2006; Melotto et al., 2020).

In recent years, taxonomic diversity has been extended to functional diversity approaches to better understand community responses to disturbances (McGill et al., 2006; Mouillot et al., 2013; Villéger et al., 2008). To that end, functional traits can be used as a biomonitoring tool (Dolédec et al., 1999). In freshwater ecosystems, invertebrate functional traits can be described as life-history strategies or evolutionary advantages to resist environmental disturbance. For example, resistance forms (e.g., resistant stages such as eggs or diapause periods) may be used by invertebrate species as synchronisation strategies to resist harsh environmental conditions, competitors or predators (Verberk et al., 2008). Several studies have focused on how IAS change native communities and decrease taxonomic diversity, but few have assessed how they can affect functional diversity and ecosystem functions (but see Hejda \& de Bello, 2013; Ilarri et al., 2018; Wong et al., 2019).

The invasive signal crayfish, Pacifastacus leniusculus (Dana, 1852), established in NE Portugal (Anastácio et al., 2019), currently is spreading and rapidly increasing in density (Sousa et al., 2019). Without native competitors, crayfish became the largest size invertebrate species in these invaded freshwater ecosystems. Some authors suggest the use of a combined approach by analysing population density and per-capita effects (Parker et al., 1999) to assess the impacts of IAS on resource availability at specific locations (Shea \& Chesson, 2002).

In this study, we aimed to assess how the presence and abundance of the invasive signal crayfish affect the taxonomic and functional trait diversity of native invertebrates, and alter a key ecosystem process, namely organic matter recycling. We hypothesised that the presence of invasive signal crayfish and its in situ abundance would lead to: (i) negative effects on native invertebrate abundance and diversity; (ii) trait-selective effects on native invertebrates by decreasing functional redundancy; (iii) direct effects on organic matter recycling by accelerating leaf litter breakdown; and (iv) indirect effects on organic matter recycling by consuming 
invertebrate detritivores that drive this process. As a combination of the per-capita and increasing abundance effects, we expected that the impacts of crayfish would change according to the invasion-level (i.e. crayfish density), and effects would be more severe at recently invaded areas with low crayfish abundance and naïve native invertebrate communities. We also expected that these impacts would alter taxonomic and functional diversity of native invertebrates with consequences to ecosystem processes.

\section{2 | MATERIALS AND METHODS}

\subsection{Study area and experimental setup}

The invasive signal crayfish was first detected in Portugal in 1997 in the Maçãs River (tributary of the Sabor River, Douro basin) (Bernardo et al., 2011) and has been spreading during the last two decades throughout the entire Sabor basin and nearby Tua basin (Anastácio et al., 2019; Meira et al., 2019; Sousa et al., 2019). In our manipulative experiment, we selected two rivers where the invasive crayfish $P$. leniusculus is currently spreading: Rabaçal and Tuela Rivers (Tua basin, NE Portugal). Rabaçal and Tuela Rivers have total lengths of 88 and $102 \mathrm{~km}$, respectively, very low human disturbance, and similar climate regarding precipitation and temperature (Nogueira et al., 2021; Sousa et al., 2018, 2020). Within both rivers, the first specimens of $P$. leniusculus were detected in 2013 (Sousa et al., 2015) and since then the species has spread rapidly from upstream to downstream, presenting higher abundance at upstream (core) areas when compared to the invasion front (Sousa et al., 2019).

Within each river, we selected three sites (Figure 1) according to the crayfish in situ abundance (absent, low, high). The absent sites were located immediately downstream the invasion front. We used in situ abundance as a variable factor in the analysis based on the assumption that the invertebrate community that accesses the experimental cages is determined by crayfish abundance at that stream location. Hereafter abundance was used as a proxy of signal crayfish population density per site. Crayfish abundances were assessed by setting eight to 10 bait traps for $24 \mathrm{hr}$ at each site (full description in Sousa et al., 2019). Therefore, relative abundance of crayfish per site was expressed as the total number of individuals per catch per unit of effort (ind. CPUE/24 hr) following Sousa et al. (2013). At Rabaçal and Tuela, crayfish low abundance corresponded to $0.3( \pm 0.8)$ and 0.5 ( \pm 0.8 ) ind. CPUE/24 hr, whereas high abundance corresponded to 26.3 ( \pm 10.1) and 26.1 ( \pm 7.9) ind. CPUE/24 hr, respectively. Physicochemical water parameters, including temperature, conductivity, percentage of oxygen saturation and nutrient concentrations, were measured at each site at the beginning, middle and end of the experiment. Temperature, conductivity and dissolved oxygen were measured with a field probe (Multiline F/set 3 no. 400327, WTW). Water samples were collected with plastic bottles and transported in a cool box $\left(4^{\circ} \mathrm{C}\right)$ to the laboratory and analysed within $24 \mathrm{hr}$, for quantifying nutrient concentration. Ammonium, nitrate and phosphate concentrations were determined using a DR/200 photometer $(\mathrm{HACH})$ and the $\mathrm{HACH}$ kit protocols (ammonium 385, nitrate 351 and

\section{Experimental sites at Rabaçal and Tuela rivers}

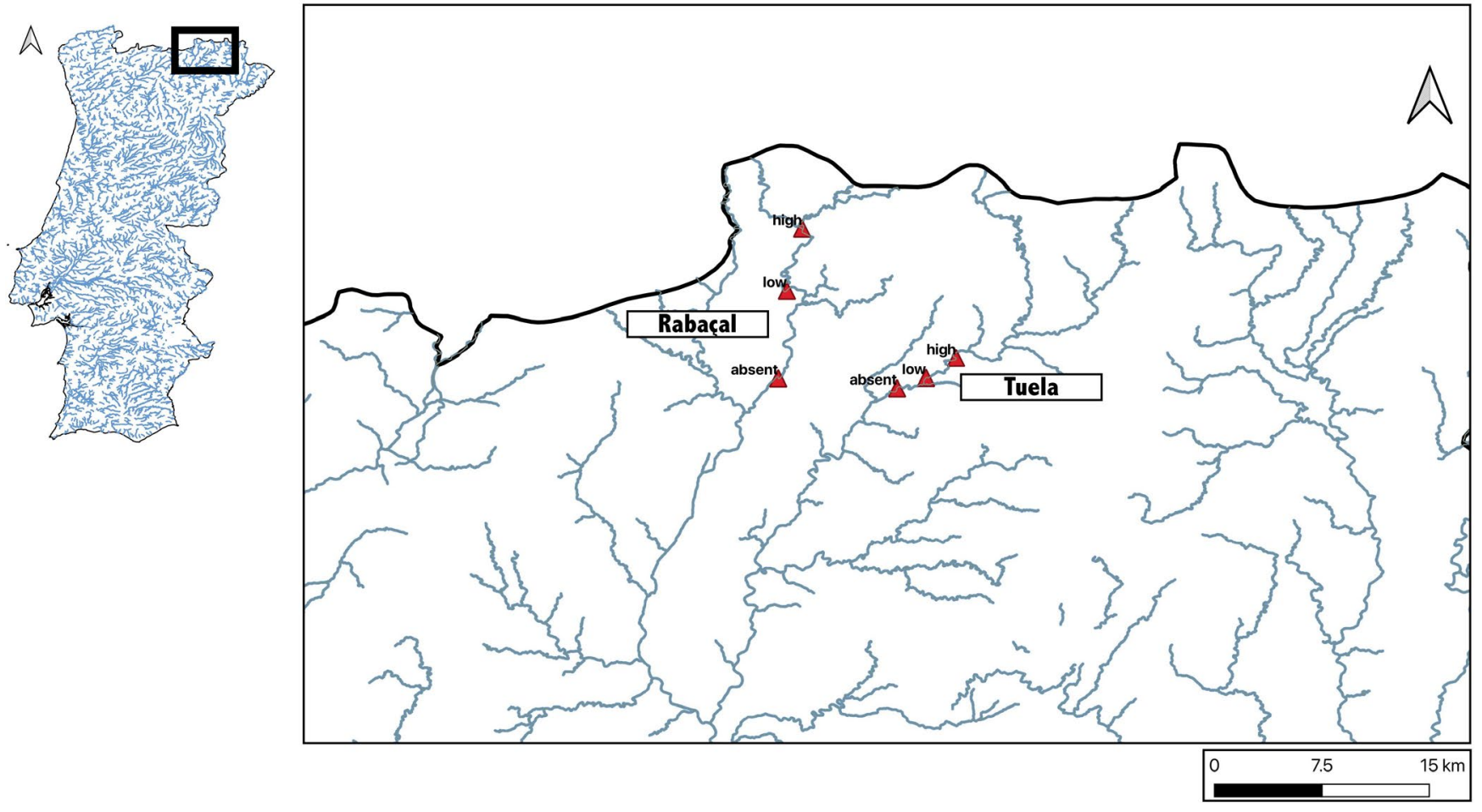

FIGURE 1 Map of the experimental sites in the Rabaçal and Tuela rivers in NE Portugal 
phosphate 490). Hydrological and habitat conditions were very similar between sites (for a full characterization, see Sousa et al., 2020).

In order to assess the direct and indirect effects of $P$. leniusculus on leaf litter breakdown and invertebrate diversity, we controlled the absence and presence of the signal crayfish (hereafter presence) inside cages $(40 \times 20 \times 20 \mathrm{~cm})$ at six sites according to its in situ abundance (absent, low, high; see above). In total, we had four treatments per site/abundance-level: (i) microbes; (ii) microbes + invertebrates; (iii) crayfish + microbes; (iv) crayfish + microbes + invertebrates. Each treatment had four replicates $(N=96)$. The presence and absence (with, without) of signal crayfish inside the cages was manipulated by adding (or not) one crayfish (adult male, $10 \mathrm{~cm}$ total length) to each cage. Inside all cages, $4 \mathrm{~g}$ oak leaves (Quercus robur L.), a common species in the riparian corridors of northern Portugal (Graça \& Poquet, 2014), collected during the abscission and air-dried, were added to further assess leaf breakdown. Cages with/without crayfish were covered with coarse- $(5 \mathrm{~mm})$ or fine-mesh $(500 \mu \mathrm{m})$ nets to allow or prevent invertebrates from accessing the leaves. By doing this, we were able to measure microbial, invertebrate and crayfish leaf breakdown individually and together. The experiment ran for 4 weeks, between 5 October and 2 November 2017.

\subsection{Invertebrate taxonomic diversity, functional redundancy and traits}

The invertebrates that entered and remained in the cages were collected with the help of a $500-\mu \mathrm{m}$ pore net when retrieving the cages from the water. After collection, animals were preserved immediately in ethanol $(76 \% \mathrm{v} / \mathrm{v})$ and transported to the laboratory. Invertebrates then were sorted and identified to the lowest possible taxonomic level (Tachet et al., 2010). In order to assess the effects of crayfish presence and abundance on invertebrate taxonomic and functional diversity, two matrices (site $\times$ taxa \& taxa $\times$ trait) were created. For the functional trait matrix, we assigned the affinity of invertebrates to five trait categories based on Tachet et al. (2010) using a fuzzy-coding approach (Chevenet et al., 1994). Selection was based on traits which could be affected by our experimental variables (crayfish presence and abundance through competition, predation or resource depletion) and included maximum potential size, resistance form, locomotion and substrate relationship, feeding habits and food source (Table S1). The affinity of invertebrates was converted to percentages for each trait in order to standardise differences in the affinity scores and modalities of each trait that were allowed to co-occur. The affinity scores for modalities and traits are available in Figure S1. Percentage of individuals for each trait modality based on taxa abundance also were calculated to assess effects of crayfish abundance and presence on specific selected functional traits. To build the functional space, a triangular matrix was created including taxa dissimilarity to reduce their dimensionality into a number of independent axes of trait variation by using an adapted version of the Gower index ideal for fuzzy-coding approaches (Pavoine et al., 2009). Functional space quality was assessed by selecting the most relevant functional axes given the optimal number of dimensions (Maire et al., 2015). Functional redundancy, a metric that indicates the average representation of organisms playing similar functional roles in the ecosystem, was calculated by classifying the species into functional groups (Figure S2) by means of clustering approaches based on a trait dissimilarity matrix (Bruno et al., 2016; Laliberté et al., 2010).

\section{3 | Leaf litter breakdown}

At the end of the experiment, leaf mass remaining inside the cages was collected, transported to the laboratory, washed and lyophilised for $48 \mathrm{~h}$, and weighed to the nearest $0.01 \mathrm{mg}$. Percentage of leaf litter breakdown $\left(L_{c}\right)$ was obtained as $L_{c}=\left(L_{i}-L_{f}\right) \times\left(100 / L_{i}\right)$, where $L_{i}$ and $L_{f}$ are the initial and final dry mass (DM, g) of leaves (following Carvalho et al., 2016).

\subsection{Data analyses}

Linear mixed models (LMMs) with Gaussian error distributions and identity link functions were used to describe the relationships between our explanatory variables: taxonomic diversity analysis, richness and Shannon diversity, functional redundancy, percentage of individuals with resistance forms, and leaf breakdown by microbes (by microbes only or by crayfish and microbes in cages excluding other invertebrates); and response variables. Models were fitted by using crayfish presence and abundance as fixed effects. To account for non-independence of the data, river was used as a random variable (Tables S2, S4 and S5). LMMs with Gaussian error distribution and loglink function were used for invertebrate abundance and for leaf breakdown by invertebrates (cages allowing the entry of invertebrates with and without the presence of crayfish). We included a variance function in models when data showed heteroscedasticity (Zuur et al., 2009).

The effects of crayfish presence and abundance on invertebrate community structure were analysed by a principal component analysis (PCA) creating two plots (based on row coordinates) for the two independent variables. Monte Carlo permutation tests were applied for the statistical effects of crayfish presence and abundance on the invertebrate community. Another PCA based on species (based on column coordinates) was performed to identify the most influential species, and SIMPER was used to check for dissimilarities in invertebrate species average abundances between the three levels of crayfish abundance (Table S3).

For functional analysis after graphically checking the most important relationships between the percentage of trait modalities and our independent variables, we calculated the percentage of individuals with resistance form and without resistance form as dependent variables. The percentage of individuals with resistance strategies included the sum of the percentages of invertebrate taxa with cocoons +eggs and statoblats +diapause or dormancy. 
All of the analyses were performed in R software v3.6.3 (R Core Team, 2021). For invertebrate taxonomic diversity, species richness and Shannon-Wiener diversity index were calculated using the "diversity" and "specnumber" functions in R/vegan (Oksanen et al., 2007). Taxonomic and functional analyses were performed with R/ade4 (Dray et al., 2007), R/adegraphics (Siberchicot et al., 2017) and R/FD (Laliberté et al., 2014).

All of the LMMs were validated by visually checking the distribution of residuals for normality and homoscedasticity (Zuur \& leno, 2016; Zuur et al., 2009). LMMs were fitted using the command "Ime" from R/nlme (Pinheiro et al., 2020). Model selection was performed by the lowest corrected Aikake information criterion (AICc) values using R/MuMin (Barton \& Barton, 2015).

\section{3 | RESULTS}

\subsection{Stream water parameters}

Stream water parameters did not vary significantly across sites with different crayfish abundance (Table S6). Temperature and oxygen saturation were similar in Tuela and Rabaçal Rivers, whereas conductivity was higher in the Tuela River (Table S6). Mean ammonium and phosphate concentrations were similar in both rivers, whereas nitrate concentration was higher in the Tuela River (Table S6).

\section{2 | Invertebrate taxonomic diversity}

Crayfish presence and abundance had a significant effect on the abundance of native invertebrates inside the cages (LMM; Table 1). The abundance of invertebrates decreased in the presence of crayfish, particularly at high crayfish abundance (Figure 2a). In the absence of crayfish inside the cages, native invertebrate abundance was significantly lower at high abundance than at absent crayfish sites (Tukey's honestly significant difference (HSD), $p=0.0305$ ).

A total of 45 invertebrate taxa were collected inside the cages. Invertebrate taxonomic richness and diversity (Shannon index) were affected by crayfish abundance, but not by crayfish presence inside the cages (LMM; Table 1). Generally, invertebrate richness was higher at crayfish absent sites (Figure $2 b$ ). In the absence of crayfish inside the cages, invertebrate richness at high crayfish abundance sites was significantly lower than at crayfish absent sites (Tukey's HSD, $p=0.0055$ ). Shannon diversity followed the same pattern and was lower at high abundance sites (Figure 2c).

PCA analysis (Figure 3 ) showed that the structure of invertebrate communities was affected by crayfish abundance (Monte Carlo permutations test, $p=0.001$ ), but not by crayfish presence inside the cages (Monte Carlo permutations test, $p=0.469$ ). The first PCA axis explained $31.82 \%$ of the total variation, and the second axis 17.92\%. The PCA showed that Caenis (13.6\%), Physella (11.5\%) and Hydropsyche (8.3\%) were the three taxa that contributed most to changes in the structure of invertebrate communities among crayfish abundance levels (Figure 3). SIMPER analysis (Table S3) showed that the top five taxa with the highest contribution to dissimilarities in invertebrate communities were Caenis, Physella, Hydropsiche, Stenelmis and Ecdyonurus (Table S3).

\section{3 | Functional redundancy}

Functional redundancy based on invertebrate traits was affected by crayfish abundance, but not by crayfish presence (LMM; Table 2). Functional redundancy was significantly higher at absent than at high abundance sites (Figure 4a; Tukey's HSD, $p=0.0391$ ). No significant differences were found in crayfish abundance $\times$ presence interactions (Tukey's HSD, $p>0.05$ ).

Among functional traits, crayfish abundance significantly affected the percentage of invertebrates with resistance strategies
TABLE 1 Results of the linear mixed models (LMMs) to test the effects of crayfish presence and abundance and their interactions on invertebrate taxonomic diversity

\begin{tabular}{|c|c|c|c|c|c|}
\hline $\begin{array}{l}\text { Response } \\
\text { variables }\end{array}$ & Fixed effects & $\begin{array}{l}\text { Num } \\
d f\end{array}$ & $\begin{array}{l}\text { Den } \\
d f\end{array}$ & F-value & $p$-value \\
\hline \multirow[t]{4}{*}{ Abundance } & (Intercept) & 1 & 38 & 216.559 & $<0.0001$ \\
\hline & Abundance & 2 & 38 & 9.713 & 0.000 \\
\hline & Presence & 1 & 38 & 4.919 & 0.033 \\
\hline & Abundance:presence & 2 & 38 & 1.014 & 0.372 \\
\hline \multirow[t]{4}{*}{ Richness } & (Intercept) & 1 & 38 & 143.772 & $<0.0001$ \\
\hline & Abundance & 2 & 38 & 14.692 & $<0.0001$ \\
\hline & Presence & 1 & 38 & 1.813 & 0.186 \\
\hline & Abundance:presence & 2 & 38 & 0.205 & 0.816 \\
\hline \multirow[t]{4}{*}{ Shannon } & (Intercept) & 1 & 38 & 249.750 & $<0.0001$ \\
\hline & Abundance & 2 & 38 & 10.460 & 0.000 \\
\hline & Presence & 1 & 38 & 0.376 & 0.543 \\
\hline & Abundance:presence & 2 & 38 & 0.039 & 0.962 \\
\hline
\end{tabular}

Note: Significant predictors are in bold. 
(a)

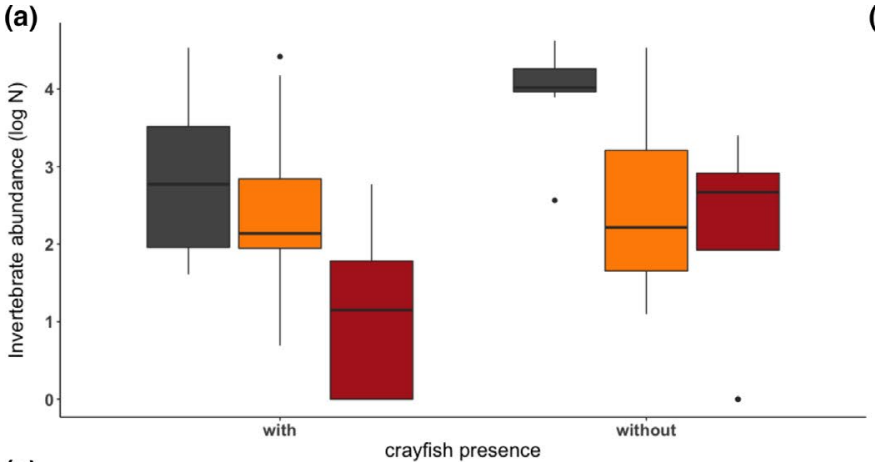

(c)

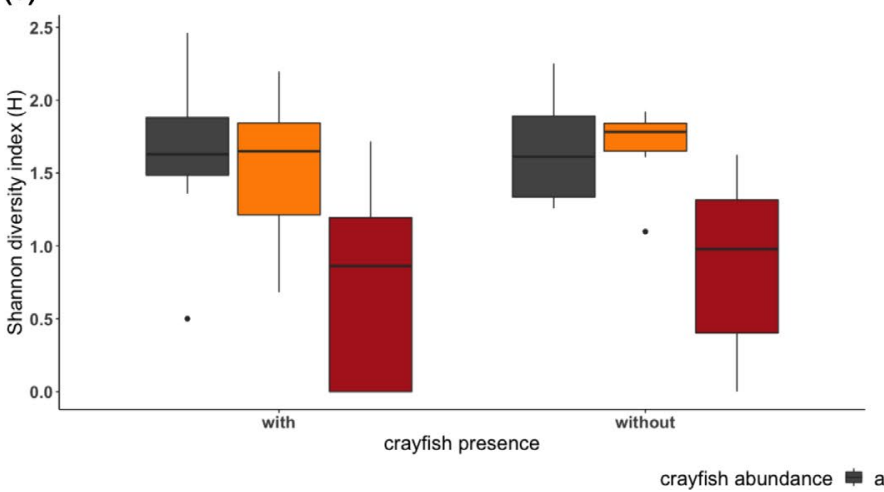

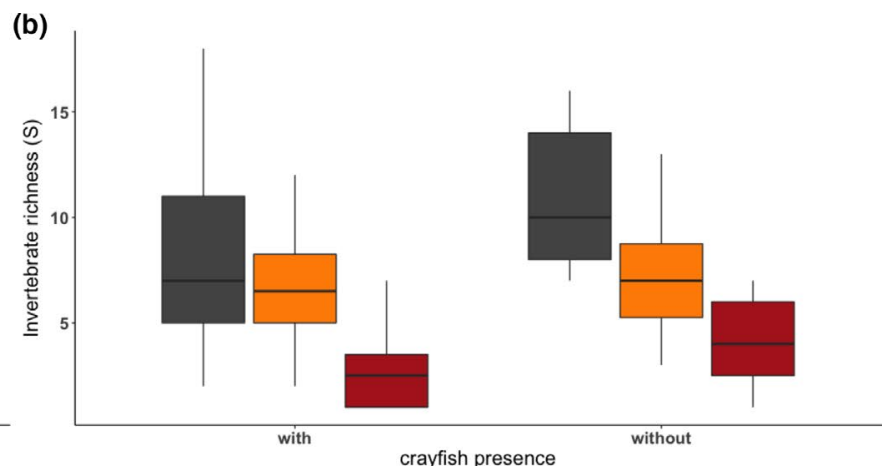

crayfish presence

FIGURE 2 Invertebrate abundance (a), richness (b) and Shannon diversity index (c) in the absence (without) and presence (with) of the signal crayfish (Pacifastacus leniusculus) at three sites with increasing levels of crayfish abundance (absent, low and high). Boxplots show median values (central line), the range from the 25th to 75th percentile (box), the largest and lowest value within 1.5 times the interquartile range below and above the 25 th and 75 th percentile (whiskers) and extreme values (dots)

(LMM; Table 2). The presence of invertebrates with resistance form strategies was significantly higher at high crayfish abundance than at low abundance or absent sites with (Tukey's HSD, $p<0.0001$ vs. $p=0.0342$, respectively) or without (Tukey's HSD, $p=0.0001$, both) crayfish inside the cages (Figure $4 b$ ). Invertebrates without resistance form strategies followed an opposite trend by decreasing with the increase in crayfish abundance (LMM; Table 2). Among the selected traits, only resistance forms were significantly affected by crayfish presence and/or abundance. The percentage of larger invertebrates decreased with the increase in crayfish abundance, but not significantly (Figure S3).

\subsection{Leaf litter breakdown}

When excluding native invertebrates, $P$. leniusculus significantly increased leaf litter breakdown driven by microbes (LMM; Table 3; Figure 5a). Leaf breakdown was significantly higher in the presence of crayfish at absent (Tukey's HSD, absent, $p=0.0019$; low, $p=0.0034$; high, $p=0.0008$ ) and at low abundance sites (Tukey's HSD, absent, $p=0.0003$; low, $p=0.0006$; high, $p=0.0001$ ) than in treatments without crayfish at all abundance sites.

In the presence of native invertebrates, leaf litter breakdown increased significantly with crayfish presence inside the cages, whereas increasing crayfish abundance did not alter leaf litter breakdown (LMM; Table 3; Figure 5b).

\section{4 | DISCUSSION}

Our results highlight that invasive signal crayfish led to an impoverishment of taxonomic and functional diversity of native invertebrates, and altered leaf litter breakdown in freshwater ecosystems. As hypothesised, signal crayfish presence and increasing abundance had a negative effect on invertebrate abundance and diversity. An increase in crayfish abundance led to a decrease in functional redundancy of native invertebrates and to a trait-selective effect (i.e., selection of invertebrate resistance form strategies). The effects of crayfish presence and abundance on leaf litter breakdown were more pronounced in treatments when excluding native invertebrates.

\section{1 | Invertebrate taxonomic diversity}

The presence and increasing abundance of the invasive crayfish $P$. leniusculus had a strong negative effect on native invertebrate abundance. Similar results have been described (Twardochleb et al., 2013), but the effects appear to vary between populations at different streams (Evangelista et al., 2019; Klose \& Cooper, 2012) or within populations among different traits (Carvalho et al., 2018). Invertebrate abundance was lower at high crayfish abundance sites in cages without the crayfish indicating higher predation impacts on invertebrate diversity in highly invaded areas. The absence of effects on invertebrates between 


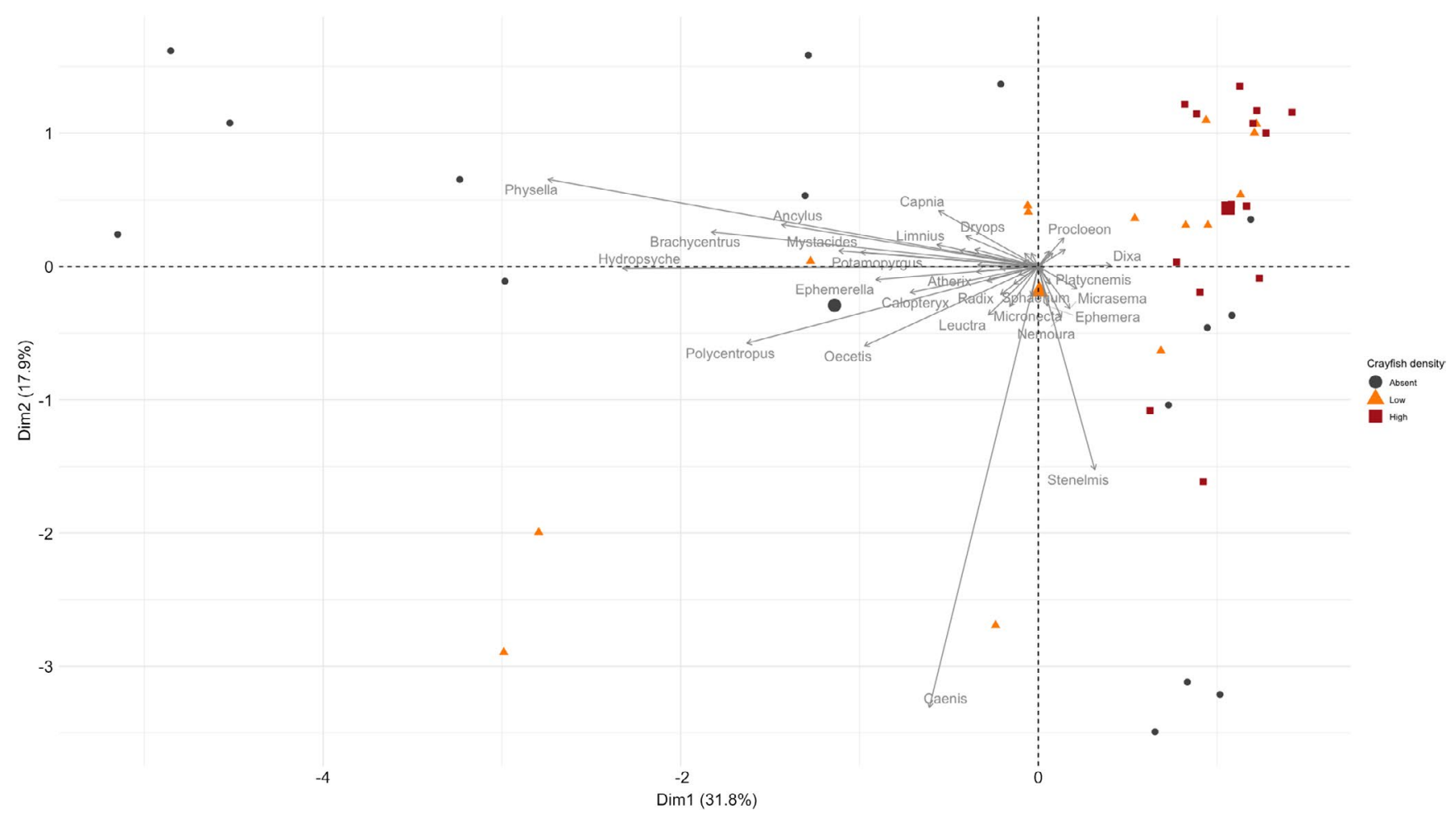

FIGURE 3 Principal component analysis (PCA) of invertebrate taxa grouped according to crayfish abundance. Invertebrate taxa of the same variable level are assigned by an ellipse. Arrows indicate invertebrate taxa with higher influence on the PCA. Longer arrows denote stronger influence on the results

TABLE 2 Results of the linear mixed models (LMMs) to test the effects of crayfish presence and abundance and their interactions on invertebrate functional diversity

\begin{tabular}{|llllll} 
& & Num & Den & & \\
Response variables & Fixed effects & $d f$ & $d f$ & F-value & $p$-value \\
\hline $\begin{array}{l}\text { Functional } \\
\text { redundancy }\end{array}$ & (Intercept) & 1 & 38 & 14.443 & 0.001 \\
& Abundance & 2 & 38 & 3.337 & 0.046 \\
& Presence & 1 & 38 & 0.244 & 0.624 \\
& Abundance:presence & 2 & 38 & 2.014 & 0.148 \\
With resistance & (Intercept) & 1 & 38 & 581.257 & $<0.0001$ \\
form & Abundance & 2 & 38 & 29.333 & $<0.0001$ \\
& Presence & 1 & 38 & 2.054 & 0.160 \\
Without resistance & Abundance:presence & 2 & 38 & 1.661 & 0.204 \\
form & (Intercept) & 1 & 38 & 294.411 & $<0.0001$ \\
& Abundance & 2 & 38 & 27.137 & $<0.0001$ \\
& Presence & 1 & 38 & 3.204 & 0.081 \\
& Abundance:presence & 2 & 38 & 0.955 & 0.394 \\
\hline
\end{tabular}

Note: Significant predictors are in bold.

crayfish abundance sites in the presence of crayfish may be attributed to predation on invertebrates that entered the cages, which may reduce differences across treatments as a combined effect of the crayfish abundance outside the cages and the per-capita effect inside the cages. Nevertheless, we also may hypothesise a potential predator avoidance behaviour of invertebrates (Nunes et al., 2014; Strauss et al., 2006) that would explain the lower numbers of invertebrates entering the cages.
Our results suggest that increasing crayfish abundance may be particularly detrimental for invertebrate richness and diversity. Additionally, per-capita effects may change with the increase in crayfish population abundance, which may increase intraspecific competition leading individuals to search for alternative food sources. This can act as a driver for increasing niche width and changes in trophic position of crayfish individuals (Jackson et al., 2017). Crayfish per-capita and abundance impacts also may have functional 
(a)

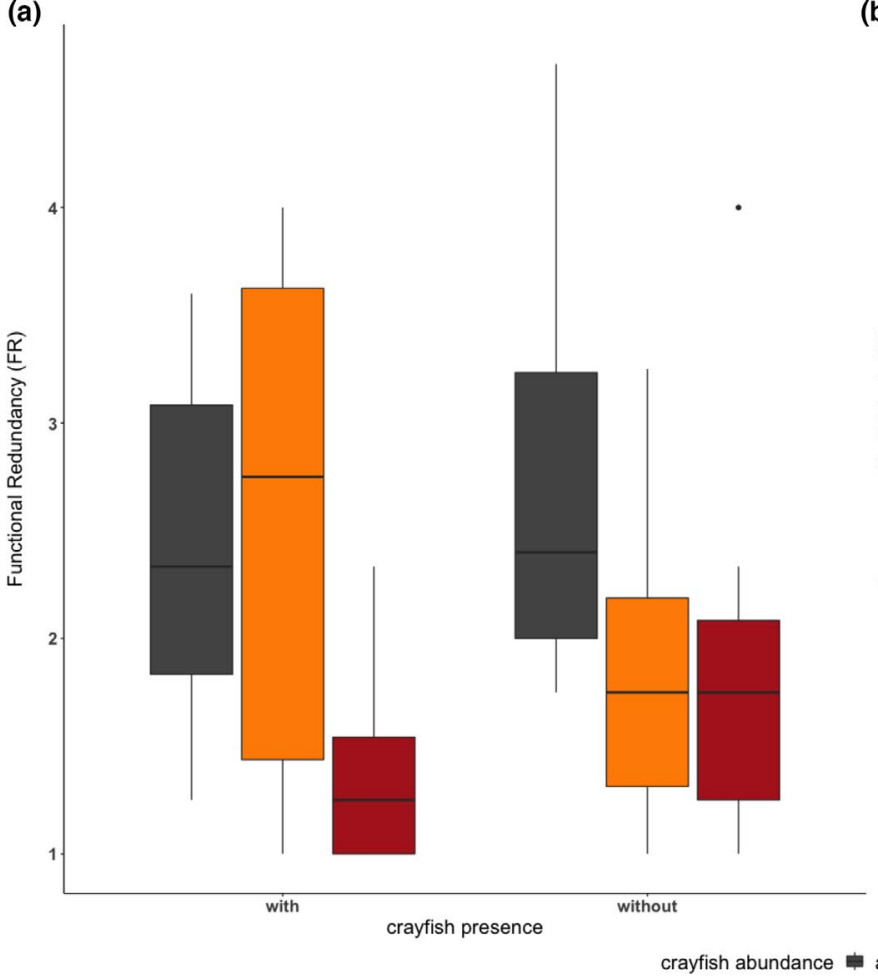

(b) With resistance forms

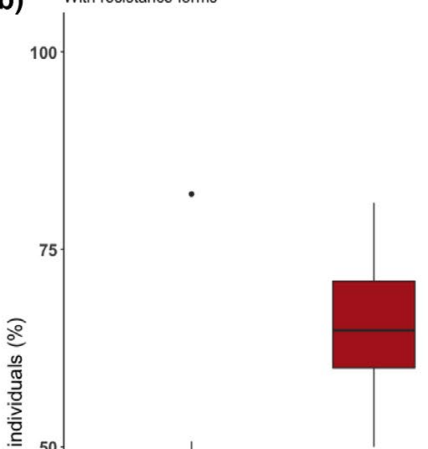

FIGURE 4 Functional redundancy (a) and percentage of individuals of invertebrate taxa with resistance form strategies (b) in the absence (without) or presence (with) of the signal crayfish (Pacifastacus leniusculus) at the three sites with increasing levels of crayfish abundance (absent, low and high). Boxplots show median values (central line), the range from the 25th to 75th percentile (box), the largest and lowest value within 1.5 times theinterquartile range below and above the 25th and 75th percentile (whiskers) and extreme values (dots)

\begin{tabular}{llllll} 
& & Num & Den & \\
Response variables & Fixed effects & $d f$ & $d f$ & F-value & $p$-value \\
\hline Microbes & (Intercept) & 1 & 41 & 236.598 & $<0.0001$ \\
& Abundance & 2 & 41 & 4.407 & 0.019 \\
& Presence & 1 & 41 & 33.927 & $<0.0001$ \\
Invertebrates & abundance:presence & 2 & 41 & 3.197 & 0.051 \\
& (Intercept) & 1 & 41 & 228.940 & $<0.0001$ \\
& Abundance & 2 & 41 & 3.005 & 0.061 \\
& Presence & 1 & 41 & 14.262 & 0.001 \\
& Abundance:presence & 2 & 41 & 1.010 & 0.373 \\
\hline
\end{tabular}

TABLE 3 Results of the linear mixed models (LMMs) to test the effects of crayfish presence and abundance and their interactions on leaf litter breakdown

Note: Significant predictors are in bold.

implications on leaf breakdown since richer and diverse invertebrate communities enhance breakdown rates through facilitation or complementarity between species (Gessner et al., 2010; Jonsson \& Malmqvist, 2000).

As expected, the crayfish in situ abundance affected the structure of invertebrate communities by decreasing their abundance, richness and diversity, regardless of the crayfish presence in the cages. A previous long-term study in England with $P$. leniusculus showed that the community structure changed in invaded areas owing to the decrease in the abundance of some species (Mathers et al., 2016). In our study, some taxa such as Ephemeroptera (Caenis spp.), Trichoptera (Hydropsyche spp.) and Gastropoda (Physella spp.) had a strong contribution to the shifts in the structure of the invertebrate community. Other studies corroborate that the presence of $P$. leniusculus has been associated with a decrease in the abundance of Ephemeroptera and Trichoptera (Mathers et al., 2016) or of Diptera and Gastropoda (Jackson et al., 2014).

In the last two decades, some authors have highlighted the importance of addressing the linearity of the density-effect curves related to IAS impacts (Benkwitt, 2015; Jackson et al., 2015; Yokomizo et al., 2009). Although this study used a non-continuous analysis of density-effect curves, our results indicate that invasive crayfish affected invertebrate diversity depending on crayfish abundance. 

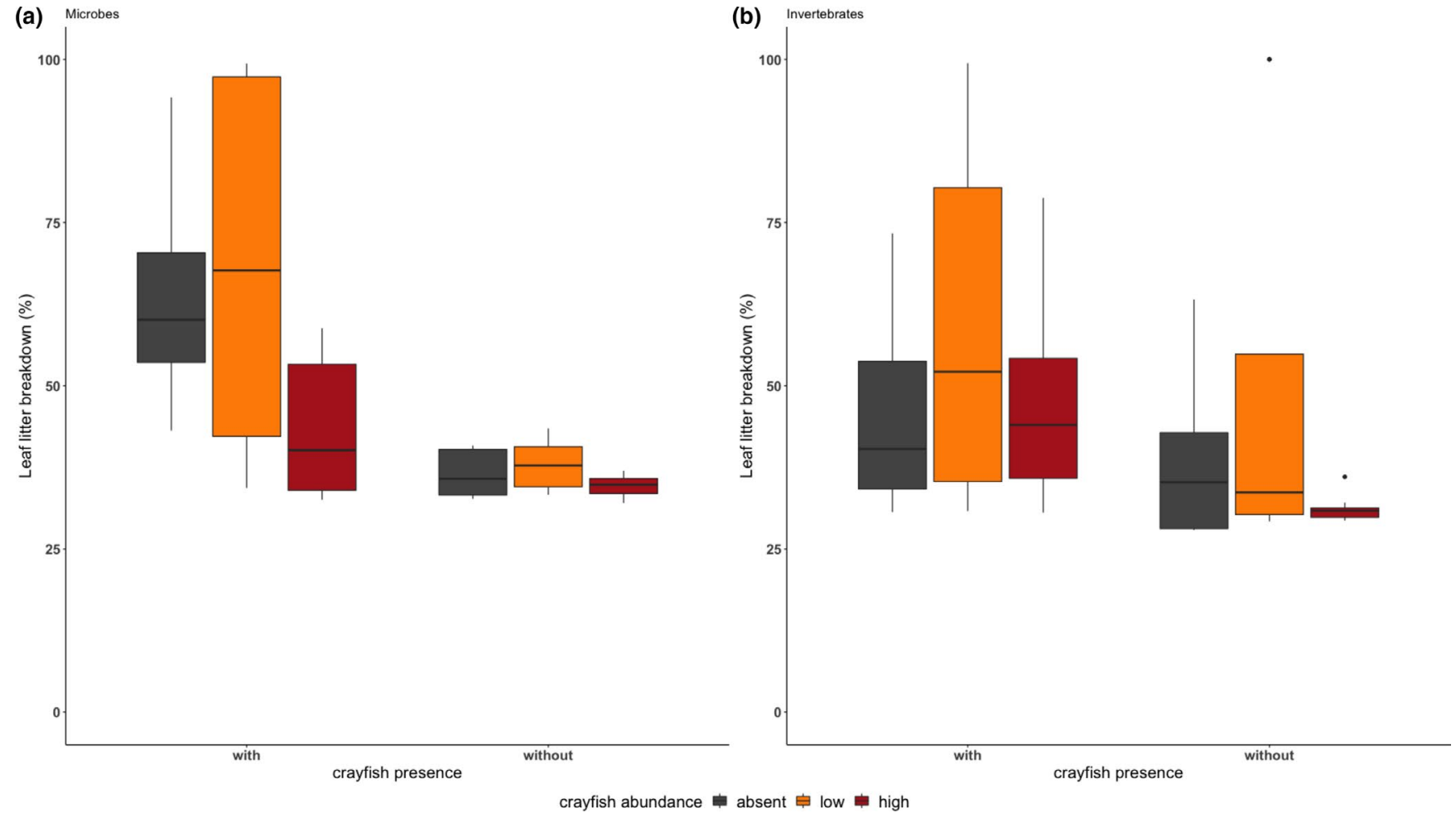

FIGURE 5 Leaf litter breakdown in the absence (without) or presence (with) of signal crayfish (Pacifastacus leniusculus) at three sites with increasing levels of crayfish abundance (absent, low and high) in the absence (a) or presence (b) of invertebrates. Boxplots show median values (central line), the range from the 25 th to 75 th percentile (box), the largest and lowest value within 1.5 times the interquartile range below and above the 25th and 75th percentile (whiskers) and extreme values (dots)

\section{2 | Functional redundancy and resistance form traits}

Invasive signal crayfish decreased the functional redundancy of native invertebrate taxa in our experiment. Functional redundancy has been used as a tool to assess ecosystem resistance to disturbances (e.g., Rosenfeld, 2002), including human-mediated ones (e.g., Laliberté et al., 2010). As expected, the decrease in taxonomic diversity was accompanied by a slight reduction in functional redundancy in response to the increase in crayfish abundance. We should consider that invertebrate communities in both rivers are particularly diverse with low human-induced disturbances besides the invasion of P. leniusculus (Nogueira et al., 2021; Sousa et al., 2019). Hence, it is expected that communities with higher diversity are more resistant to disturbances as a result of their functional redundancy (Lecerf \& Richardson, 2010). Considering that P. leniusculus introduction was recent, and that the species is still spreading and increasing in abundance in the studied rivers, it is possible that patterns can change in the future. Moreover, our results indicate that increasing crayfish abundance may lead to a decrease in the percentage of invertebrates with resistance traits in natural communities accompanied by a decrease in functional redundancy with possible implications for ecosystem functioning in the long term.

Specific trait analysis of the invertebrate community showed that the percentage of larger invertebrates tended to decrease with the increase in crayfish abundance. However, only resistance form traits were significantly affected, and effects were mediated by crayfish abundance. Although the percentage of invertebrates with resistance strategies increased at high crayfish abundance, an opposite trend was observed for invertebrate taxa without resistance form strategies. Resistance form strategies are indicative of increased invertebrate species resistance against disturbances, including predation (Verberk et al., 2008). IAS are sometimes considered as evolutionary traps for native species. This may happen when some native species traits are selected as evolutionary advantages, or from learning, when native species develop specific defences against the invader (Schlaepfer et al., 2005). Native species may have defensive behaviour against recognised native predators, although naïve against recently introduced invasive predators (Kuehne \& Olden, 2012). However, after some time in contact with invasive predators, native prey are able to develop evolutionary defensive responses or strategies against IAS (e.g., Freeman \& Byers, 2006; Melloto et al. 2020). Our results indicate that $P$. leniusculus may have an important role in native invertebrate ecology, physiology and evolution because invertebrate taxa with resistance strategies may be less impacted by crayfish within invaded ecosystems, particularly at higher densities. Other studies in freshwater ecosystems demonstrated that invasive aquatic macrophytes (Michelan et al., 2010) or invasive bivalves (Ilarri et al., 2018) impact functional diversity by changing habitat properties and complexity. Predation by IAS also may have significant effects on 
native communities at the taxonomic and functional levels (Pool \& Olden, 2012). Our results show that effects of invasive crayfish abundance on invertebrates are decreasing both species taxonomic diversity and functional redundancy, while potentially selecting for some traits, which may reconfigure the future invaded invertebrate community with consequences for ecosystem functioning, such as plant litter breakdown.

\section{3 | Leaf litter breakdown}

The presence and abundance of $P$. leniusculus stimulated leaf litter breakdown. Our results showed that in the absence of native invertebrates, the invasive signal crayfish was able to contribute to leaf litter breakdown, except at high crayfish abundance sites. This may be explained by a decrease in the feeding behaviour by sensing conspecifics outside the cages. This is supported by observations that crayfish usually forage on a diverse range of resources at low density and may decrease their activity in highdensity areas (Jackson et al., 2015). Evidence from mesocosm experiments also reported increasing intraspecific aggression and per capita interactions with increasing crayfish densities (Pintor et al., 2009).

Leaf litter breakdown was not affected by increasing crayfish abundance in treatments where both the invasive signal crayfish and other invertebrates were inside the cages. At low crayfish in situ abundance, leaf breakdown was higher when the signal crayfish and other invertebrates were together. Both native invertebrates and invasive crayfish may contribute to enhanced leaf breakdown at low abundance sites. Likewise, increased leaf breakdown rates were observed with native invertebrates (Gammarus spp.) and invasive crayfish in sympatry (Dunoyer et al., 2014). However, leaf litter breakdown can be also reduced indirectly via trophic cascades as a consequence of predation by invasive crayfish on native invertebrates (Lagrue et al., 2014; Moore et al., 2012). Possible explanation for the lower leaf breakdown at absent sites in the presence of crayfish inside the cages may be the higher diversity and abundance of naïve invertebrates that provide an alternative food source for crayfish.

Pristine rivers, such as the ones where we ran our experiment (Nogueira et al., 2021), are expected to have high biodiversity and consequently high functional redundancy, making them more resistant and resilient to disturbances (Woodward, 2009). It is possible that the decrease in biodiversity imposed by crayfish did not lead to significant indirect effects on leaf breakdown as a result of functional redundancy. Although leaf breakdown by invertebrates in treatments without the crayfish tended to decrease with the increase in crayfish in situ abundance, the results were only marginally statistically significant. This suggests that with time, and if the population density of the invasive crayfish increases, the effects on native communities may lead to an indirect decrease in leaf breakdown, but this hypothesis needs to be further investigated.

\section{5 | CONCLUSION}

Overall, our results indicate that the presence of the invasive crayfish $P$. leniusculus was responsible for important ecological effects. The increases in crayfish in situ abundance led to a decrease in taxonomic and functional diversity of native invertebrates by enhancing trait selection pressures, culminating in changes in the dynamics of leaf litter breakdown in freshwater ecosystems.

In our sampled rivers, stream water characteristics were similar and indicated a very low human disturbance, as reported previously (Nogueira et al., 2021; Sousa et al., 2018, 2020), discarding the influence of water chemistry (or other environmental factors) on the observed effects and highlighting the negative impacts of the invasive signal crayfish on these ecosystems. The presence of $P$. leniusculus in both study rivers is relatively recent, nevertheless their effects were already detrimental for endangered species (e.g., Margaritifera margaritifera; Sousa et al., 2019). Our results also indicated that the invasive signal crayfish changed the detritus-based food web by affecting organic matter breakdown. Further studies should consider how abiotic and biotic factors influence the observed crayfish effects. The ecological effects mediated by the signal crayfish may significantly change in other environmental contexts (temperature, pollution) or in the presence of native or non-native predators (e.g., Lutra lutra, Neovison vison and Salmo trutta), and these situations deserve further attention.

\section{ACKNOWLEDGEMENTS}

We acknowledge Fernando Miranda and Daniela Batista for their support during field work, and Caetano GutierrezCánovas and Sylvain Dolédec for sharing their knowledge on trait analysis.

\section{AUTHOR CONTRIBUTIONS}

FC, CP and RS conceived the study. All authors collected data. FC ran analyses. FC wrote the first draft with the help of CP, FC and RS. All authors contributed to the writing with comments and suggestions, and approved the final version.

\section{DATA AVAILABILITY STATEMENT}

Data are available from the authors upon request.

\section{ORCID}

Francisco Carvalho (D) https://orcid.org/0000-0002-8414-9587

Cláudia Pascoal (D) https://orcid.org/0000-0002-2018-4201

Fernanda Cássio (iD https://orcid.org/0000-0003-3924-3280

Amílcar Teixeira (D) https://orcid.org/0000-0001-5336-1174

Ronaldo Sousa (D) https://orcid.org/0000-0002-5961-5515

\section{REFERENCES}

Anastácio, P. M., Ribeiro, F., Capinha, C., Banha, F., Gama, M., Filipe, A. F., ... Sousa, R. (2019). Non-native freshwater fauna in Portugal: A review. Science of the Total Environment, 650, 1923-1934. https:// doi.org/10.1016/j.scitotenv.2018.09.251 
Atwood, T. B., Hammill, E., Greig, H. S., Kratina, P., Shurin, J. B., Srivastava, D. S., \& Richardson, J. S. (2013). Predator-induced reduction of freshwater carbon dioxide emissions. Nature Geoscience, 6, 191 194. https://doi.org/10.1038/ngeo1734

Bacher, S., Blackburn, T. M., Essl, F., Genovesi, P., Heikkilä, J., Jeschke, J. M., ... Martinou, A. F. (2018). Socio-economic impact classification of alien taxa (SEICAT). Methods in Ecology and Evolution, 9, 159-168.

Barney, J. N., Ho, M. W., \& Atwater, D. Z. (2016). Propagule pressure cannot always overcome biotic resistance: The role of densitydependent establishment in four invasive species. Weed Research, 56, 208-218. https://doi.org/10.1111/wre.12204

Barton, K., \& Barton, M. K. (2015). Package 'MuMIn.' Version 1, 18.

Benkwitt, C. E. (2015). Non-linear effects of invasive lionfish density on native coral-reef fish communities. Biological Invasions, 17, 13831395. https://doi.org/10.1007/s10530-014-0801-3

Bernardo, J. M., Costa, A. M., Bruxelas, S., \& Teixeira, A. (2011). Dispersal and coexistence of two non-native crayfish species (Pacifastacus leniusculus and Procambarus clarkii) in NE Portugal over a 10 -year period. Knowledge and Management of Aquatic Ecosystems, 401, 28.

Blackburn, T. M., Essl, F., Evans, T., Hulme, P. E., Jeschke, J. M., Kühn, I., Kumschick, S., ... Bacher, S. (2014). A unified classification of alien species based on the magnitude of their environmental impacts. PLoS Biology, 12, e1001850. https://doi.org/10.1371/journ al.pbio.1001850

Bruno, D., Gutiérrez-Cánovas, C., Velasco, J., \& Sánchez-Fernández, D. (2016). Functional redundancy as a tool for bioassessment: A test using riparian vegetation. Science of the Total Environment, 566-567, 1268-1276. https://doi.org/10.1016/j.scitotenv.2016.05.186

Buckley, Y. M. (2017). Invasion ecology: Unpredictable arms race in a jam jar. Nature Ecology \& Evolution, 1, 1-2. https://doi.org/10.1038/ s41559-016-0028

Carpenter, S. R., Stanley, E. H., \& Vander Zanden, M. J. (2011). State of the world's freshwater ecosystems: Physical, chemical, and biological changes. Annual Review of Environment and Resources, 36, 75-99. https://doi.org/10.1146/annurev-environ021810-094524

Carvalho, F., Pascoal, C., Cássio, F., \& Sousa, R. (2016). Direct and indirect effects of an invasive omnivore crayfish on leaf litter decomposition. Science of the Total Environment, 541, 714-720. https://doi. org/10.1016/j.scitotenv.2015.09.125

Carvalho, F., Pascoal, C., Cássio, F., \& Sousa, R. (2018). Effects of intrapopulation phenotypic traits of invasive crayfish on leaf litter processing. Hydrobiologia, 819, 67-75. https://doi.org/10.1007/ s10750-018-3631-y

Chevenet, F., Doledéc, S., \& Chessel, D. (1994). A fuzzy coding approach for the analysis of long-term ecological data. Freshwater Biology, 31 295-309. https://doi.org/10.1111/j.1365-2427.1994.tb01742.x

Clavel, J., Julliard, R., \& Devictor, V. (2011). Worldwide decline of specialist species: Toward a global functional homogenization? Frontiers in Ecology and the Environment, 9, 222-228. https://doi. org/10.1890/080216

Covich, A. P., Palmer, M. A., \& Crowl, T. A. (1999). The role of benthic invertebrate species in freshwater ecosystems: Zoobenthic species influence energy flows and nutrient cycling. BioScience, 49, 119127. https://doi.org/10.2307/1313537

Dawson, M. N. (2012). Species richness, habitable volume, and species densities in freshwater, the sea, and on land. Frontiers of Biogeography, 4(3), 105-116.

Dolédec, S., Statzner, B., \& Bournard, M. (1999). Species traits for future biomonitoring across ecoregions: Patterns along a humanimpacted river. Freshwater Biology, 42, 737-758. https://doi. org/10.1046/j.1365-2427.1999.00509.x

Downing, A. S., van Nes, E. H., Mooij, W. M., \& Scheffer, M. (2012). The resilience and resistance of an ecosystem to a collapse of diversity. PLoS One, 7(9), e46135.
Dray, S., Dufour, A. B., \& Chessel, D. (2007). The ade4 package-II: Twotable and K-table methods. Package 'ade4' (2 ed., Vol. 7, pp. 47-52). R news. https://cran.r-project.org/doc/Rnews/

Dudgeon, D., Arthington, A. H., Gessner, M. O., Kawabata, Z.-I., Knowler, D. J., Lévêque, C., ... Sullivan, C. A. (2006). Freshwater biodiversity: Importance, threats, status and conservation challenges. Biological Reviews of the Cambridge Philosophical Society, 81(02), 163. https:// doi.org/10.1017/S1464793105006950

Dunck, B., Lima-Fernandes, E., Cássio, F., Cunha, A., Rodrigues, L., \& Pascoal, C. (2015). Responses of primary production, leaf litter decomposition and associated communities to stream eutrophication. Environmental Pollution, 202, 32-40. https://doi.org/10.1016/j. envpol.2015.03.014

Dunoyer, L., Dijoux, L., Bollache, L., \& Lagrue, C. (2014). Effects of crayfish on leaf litter breakdown and shredder prey: Are native and introduced species functionally redundant? Biological Invasions, 16, 1545-1555. https://doi.org/10.1007/s10530-013-0590-0

Ehrenfeld, J. G. (2010). Ecosystem consequences of biological invasions. Annual Review of Ecology, Evolution, and Systematics, 41, 59-80. https://doi.org/10.1146/annurev-ecolsys-102209-144650

Evangelista, C., Cucherousset, J., \& Lecerf, A. (2019). Contrasting ecological impacts of geographically close invasive populations. Oecologia, 189, 529-536. https://doi.org/10.1007/s00442-018-04333-5

Freeman, A. S., \& Byers, J. E. (2006). Divergent induced responses to an invasive predator in marine mussel populations. Science, 313, $831-$ 833. https://doi.org/10.1126/science.1125485

Gallardo, B., Clavero, M., Sánchez, M. I., \& Vilà, M. (2016). Global ecological impacts of invasive species in aquatic ecosystems. Global Change Biology, 22, 151-163. https://doi.org/10.1111/gcb.13004

Gessner, M. O., Swan, C. M., Dang, C. K., McKie, B. G., Bardgett, R. D., Wall, D. H., \& Hättenschwiler, S. (2010). Diversity meets decomposition. Trends in Ecology \& Evolution, 25, 372-380. https://doi. org $/ 10.1016 / j$.tree.2010.01.010

Graça, M. A. S. (2001). The role of invertebrates on leaf litter decomposition in streams - A review. International Review of Hydrobiology, 86, 383-393.

Graça, M. A. S., \& Poquet, J. M. (2014). Do climate and soil influence phenotypic variability in leaf litter, microbial decomposition and shredder consumption? Oecologia, 174, 1021-1032. https://doi. org/10.1007/s00442-013-2825-2

Gulis, V., Ferreira, V., \& Graça, M. A. S. (2006). Stimulation of leaf litter decomposition and associated fungi and invertebrates by moderate eutrophication: Implications for stream assessment. Freshwater Biology, 51, 1655-1669. https://doi. org/10.1111/j.1365-2427.2006.01615.x

Gutiérrez, J. L., Jones, C. G., \& Sousa, R. (2014). Toward an integrated ecosystem perspective of invasive species impacts. Acta Oecologica, 54, 131-138. https://doi.org/10.1016/j.actao.2013.10.003

Havel, J. E., Kovalenko, K. E., Thomaz, S. M., Amalfitano, S., \& Kats, L. B. (2015). Aquatic invasive species: Challenges for the future. Hydrobiologia, 750, 147-170. https://doi.org/10.1007/s1075 0-014-2166-0

Hejda, M., \& de Bello, F. (2013). Impact of plant invasions on functional diversity in the vegetation of Central Europe. Journal of Vegetation Science, 24, 890-897. https://doi.org/10.1111/jvs.12026

Ilarri, M. I., Amorim, L., Souza, A. T., \& Sousa, R. (2018). Physical legacy of freshwater bivalves: Effects of habitat complexity on the taxonomical and functional diversity of invertebrates. Science of the Total Environment, 634, 1398-1405. https://doi.org/10.1016/j.scito tenv.2018.04.070

Jackson, M. C., Evangelista, C., Zhao, T., Lecerf, A., Britton, J. R., \& Cucherousset, J. (2017). Between-lake variation in the trophic ecology of an invasive crayfish. Freshwater Biology, 62, 1501-1510. https://doi.org/10.1111/fwb.12957

Jackson, M. C., Jones, T., Milligan, M., Sheath, D., Taylor, J., Ellis, A., ... Grey, J. (2014). Niche differentiation among invasive crayfish and 
their impacts on ecosystem structure and functioning. Freshwater Biology, 59, 1123-1135. https://doi.org/10.1111/fwb.12333

Jackson, M. C., Ruiz-Navarro, A., \& Britton, J. R. (2015). Population density modifies the ecological impacts of invasive species. Oikos, 124 , 880-887. https://doi.org/10.1111/oik.01661

Jarić, I., Heger, T., Castro Monzon, F., Jeschke, J. M., Kowarik, I., McConkey, K. R., ... Essl, F. (2019). Crypticity in biological invasions. Trends in Ecology \& Evolution, 34, 291-302. https://doi. org/10.1016/j.tree.2018.12.008

Jonsson, M., \& Malmqvist, B. (2000). Ecosystem process rate increases with animal species richness: Evidence from leafeating, aquatic insects. Oikos, 89, 519-523. https://doi. org/10.1034/j.1600-0706.2000.890311.x

Klose, K., \& Cooper, S. D. (2012). Contrasting effects of an invasive crayfish (Procambarus clarkii) on two temperate stream communities. Freshwater Biology, 57, 526-540. https://doi. org/10.1111/j.1365-2427.2011.02721.x

Kuehne, L. M., \& Olden, J. D. (2012). Prey naivety in the behavioural responses of juvenile Chinook salmon (Oncorhynchus tshawytscha) to an invasive predator. Freshwater Biology, 57, 1126-1137. https:// doi.org/10.1111/j.1365-2427.2012.02776.x

Kumschick, S., Gaertner, M., Vilà, M., Essl, F., Jeschke, J. M., Pyšek, P., ... Winter, M. (2015). Ecological impacts of alien species: Quantification, scope, caveats, and recommendations. BioScience, 65, 55-63. https://doi.org/10.1093/biosci/biu193

Lagrue, C., Podgorniak, T., Lecerf, A., \& Bollache, L. (2014). An invasive species may be better than none: Invasive signal and native noble crayfish have similar community effects. Freshwater Biology, 59, 1982-1995. https://doi.org/10.1111/fwb.12401

Laliberté, E., Wells, J. A., DeClerck, F., Metcalfe, D. J., Catterall, C. P., Queiroz, C., ...Mayfield, M. M. (2010). Land-use intensification reduces functional redundancy and response diversity in plant communities. Ecology Letters, 13, 76-86. https://doi org/10.1111/j.1461-0248.2009.01403.x

Laliberté, E., Legendre, P., Shipley, B., \& Laliberté, M. E. (2014). Package 'FD.' Measuring functional diversity from multiple traits, and other tools for functional ecology. Version 1.0-12. https://CRAN.R-project.org/ package $=F D$

Lecerf, A., \& Richardson, J. S. (2010). Biodiversity-ecosystem function research: Insights gained from streams. River Research and Applications, 26, 45-54.

Maire, E., Grenouillet, G., Brosse, S., \& Villéger, S. (2015). How many dimensions are needed to accurately assess functional diversity? A pragmatic approach for assessing the quality of functional spaces. Global Ecology and Biogeography, 24, 728-740. https://doi. org/10.1111/geb.12299

Marean, C. W. (2015). The most invasive species of all. Scientific American 313, 32-39. https://doi.org/10.1038/scientificamerican0815-32

Mathers, K. L., Chadd, R. P., Dunbar, M. J., Extence, C. A., Reeds, J., Rice, S. P., \& Wood, P. J. (2016). The long-term effects of invasive signal crayfish (Pacifastacus leniusculus) on instream macroinvertebrate communities. Science of the Total Environment, 556, 207-218. https://doi.org/10.1016/j.scitotenv.2016.01.215

Melotto, A., Manenti, R., \& Ficetola, G. F. (2020). Rapid adaptation to invasive predators overwhelms natural gradients of intraspecific variation. Nature communications, 11(1), 1-10.

McGill, B. J., Enquist, B. J., Weiher, E., \& Westoby, M. (2006). Rebuilding community ecology from functional traits. Trends in Ecology and Evolution, 21, 178-185. https://doi.org/10.1016/j.tree.2006.02.002

Meira, A., Lopes-Lima, M., Varandas, S., Teixeira, A., Arenas, F., \& Sousa, R. (2019). Invasive crayfishes as a threat to freshwater bivalves: Interspecific differences and conservation implications. Science of the Total Environment, 649, 938-948. https://doi.org/10.1016/j. scitotenv.2018.08.341
Michelan, T. S., Thomaz, S. M., Mormul, R. P., \& Carvalho, P. (2010) Effects of an exotic invasive macrophyte (tropical signalgrass) on native plant community composition, species richness and functional diversity. Freshwater Biology, 55, 1315-1326. https://doi. org/10.1111/j.1365-2427.2009.02355.x

Mooney, H. A., \& Cleland, E. E. (2001). The evolutionary impact of invasive species. Proceedings of the National Academy of Sciences of the United States of America, 98, 5446-5451. https://doi.org/10.1073/ pnas.091093398

Moore, J. W., Carlson, S. M., Twardochleb, L. A., Hwan, J. L., Fox, J. M., \& Hayes, S. A. (2012). Trophic tangles through time? Opposing direct and indirect effects of an invasive omnivore on stream ecosystem processes. PLoS One, 7, e50687. https://doi.org/10.1371/journ al.pone.0050687

Mouillot, D., Graham, N. A. J., Villéger, S., Mason, N. W. H., \& Bellwood, D. R. (2013). A functional approach reveals community responses to disturbances. Trends in Ecology and Evolution, 28, 167-177. https:// doi.org/10.1016/j.tree.2012.10.004

Nogueira, J. G., Teixeira, A., Varandas, S., Lopes-Lima, M., \& Sousa, R. (2021). Assessment of a terrestrial protected area for the conservation of freshwater biodiversity. Aquatic Conservation: Marine and Freshwater Ecosystems, 31(3), 520-530.

Nunes, A. L., Orizaola, G., Laurila, A., \& Rebelo, R. (2014). Rapid evolution of constitutive and inducible defenses against an invasive predator. Ecology, 95, 1520-1530. https://doi.org/10.1890/13-1380.1

Oksanen, J., Kindt, R., Legendre, P., O'Hara, B., Stevens, M. H. H., Oksanen, M. J., \& Suggests, M. A. (2007). The vegan package. Community Ecology Package, 10, 719.

Olden, J. D. (2006). Biotic homogenization: A new research agenda for conservation biogeography. Journal of Biogeography, 33, 20272039. https://doi.org/10.1111/j.1365-2699.2006.01572.x

Olden, J. D., Poff, N. L., Douglas, M. R., Douglas, M. E., \& Fausch, K. D. (2004). Ecological and evolutionary consequences of biotic homogenization. Trends in Ecology \& Evolution, 19, 18-24. https://doi. org/10.1016/j.tree.2003.09.010

Parker, I. M., Simberloff, D., Lonsdale, W. M., Goodell, K., Wonham, M., Kareiva, P. M., ... Goldwasser, L. (1999). Impact: Toward a framework for understanding the ecological effects of invaders. Biological Invasions, 1, 3-19.

Pavoine, S., Vallet, J., Dufour, A.-B., Gachet, S., \& Daniel, H. (2009). On the challenge of treating various types of variables: Application for improving the measurement of functional diversity. Oikos, 118, 391-402. https://doi.org/10.1111/j.1600-0706.2009.16668.x

Pereira, A., Geraldes, P., Lima-Fernandes, E., Fernandes, I., Cássio, F., \& Pascoal, C. (2016). Structural and functional measures of leaf-associated invertebrates and fungi as predictors of stream eutrophication. Ecological Indicators, 69, 648-656. https://doi. org/10.1016/j.ecolind.2016.05.017

Pimentão, A. R., Pascoal, C., Castro, B. B., \& Cássio, F. (2020). Fungistatic effect of agrochemical and pharmaceutical fungicides on nontarget aquatic decomposers does not translate into decreased fungi-or invertebrate-mediated decomposition. Science of the Total Environment, 712, 135676. https://doi.org/10.1016/j.scito tenv.2019.135676

Pinheiro, J., Bates, D., DebRoy, S., Sarkar, D., \& R Core Team. (2020). nlme: Linear and nonlinear mixed effects models. $\mathrm{R}$ package version 3.1-149. https://CRAN.R-project.org/package $=$ nlme

Pintor, L. M., Sih, A., \& Kerby, J. L. (2009). Behavioral correlations provide a mechanism for explaining high invader densities and increased impacts on native prey. Ecology, 90, 581-587. https://doi. org/10.1890/08-0552.1

Pool, T. K., \& Olden, J. D. (2012). Taxonomic and functional homogenization of an endemic desert fish fauna. Diversity and Distributions, 18, 366-376. https://doi.org/10.1111/j.1472-4642.2011.00836.x 
Pyšek, P., Hulme, P. E., Simberloff, D., Bacher, S., Blackburn, T. M. Carlton, J. T., ... Richardson, D. M. (2020). Scientists' warning on invasive alien species. Biological Reviews, 95, 1511-1534. https://doi. org/10.1111/brv.12627

$R$ Core Team. (2021). R: A language and environment for statistical computing. R Foundation for Statistical Computing. https://www.R-proje ct.org/

Reid, A. J., Carlson, A. K., Creed, I. F., Eliason, E. J., Gell, P. A., Johnson, P. T. J., ... Cooke, S. J. (2019). Emerging threats and persistent conservation challenges for freshwater biodiversity. Biological Reviews, 94, 849-873. https://doi.org/10.1111/brv.12480

Rosenfeld, J. S. (2002). Functional redundancy in ecology and conservation. Oikos, 98, 156-162. https://doi. org/10.1034/j.1600-0706.2002.980116.x

Schlaepfer, M. A., Sherman, P. W., Blossey, B., \& Runge, M. C. (2005). Introduced species as evolutionary traps. Ecology Letters, 8, 241246. https://doi.org/10.1111/j.1461-0248.2005.00730.x

Shea, K., \& Chesson, P. (2002). Community ecology theory as a framework for biological invasions. Trends in Ecology \& Evolution, 17, 170 176. https://doi.org/10.1016/S0169-5347(02)02495-3

Siberchicot, A., Julien-Laferriere, A., Dufour, A., Thioulouse, J., \& Dray, S. (2017). adegraphics: An S4 lattice-based package for the representation of multivariate data (2 ed., Vol. 9, pp. 198-212). The R Journal. https://journal.r-project.org/archive/2017/RJ-2017-042/index. html

Simberloff, D., Martin, J.-L., Genovesi, P., Maris, V., Wardle, D. A., Aronson, J., ... Vilà, M. (2013). Impacts of biological invasions: What's what and the way forward. Trends in Ecology and Evolution, 28, 58-66. https://doi.org/10.1016/j.tree.2012.07.013

Sousa, R., Amorim, Â., Froufe, E., Varandas, S., Teixeira, A., \& LopesLima, M. (2015). Conservation status of the freshwater pearl mussel Margaritifera margaritifera in Portugal. Limnologica, 50, 4-10. https://doi.org/10.1016/j.limno.2014.07.004

Sousa, R., Ferreira, A., Carvalho, F., Lopes-Lima, M., Varandas, S., \& Teixeira, A. (2018). Die-offs of the endangered pearl mussel Margaritifera margaritifera during an extreme drought. Aquatic Conservation: Marine and Freshwater Ecosystems, 28, 1244-1248. https://doi.org/10.1002/aqc.2945

Sousa, R., Ferreira, A., Carvalho, F., Lopes-Lima, M., Varandas, S., Teixeira, A., \& Gallardo, B. (2020). Small hydropower plants as a threat to the endangered pearl mussel Margaritifera margaritifera. Science of the Total Environment, 719, 137361. https://doi.org/10.1016/j.scito tenv.2020.137361

Sousa, R., Freitas, F. E. P., Mota, M., Nogueira, A. J. A., \& Antunes, C. (2013). Invasive dynamics of the crayfish Procambarus clarkii (Girard, 1852) in the international section of the River Minho (NW of the Iberian Peninsula). Aquatic Conservation: Marine and Freshwater Ecosystems, 23, 656-666. https://onlinelibrary.wiley. com/doi/full/10.1002/aqc. 2323

Sousa, R., Gutiérrez, J. L., \& Aldridge, D. C. (2009). Non-indigenous invasive bivalves as ecosystem engineers. Biological Invasions, 11, 23672385. https://doi.org/10.1007/s10530-009-9422-7

Sousa, R., Morais, P., Dias, E., \& Antunes, C. (2011). Biological invasions and ecosystem functioning: Time to merge. Biological Invasions, 13 1055-1058. https://doi.org/10.1007/s10530-011-9947-4

Sousa, R., Nogueira, J. G., Ferreira, A., Carvalho, F., Lopes-Lima, M., Varandas, S., \& Teixeira, A. (2019). A tale of shells and claws: The signal crayfish as a threat to the pearl mussel Margaritifera margaritifera in Europe. Science of the Total Environment, 665, 329-337. https://doi.org/10.1016/j.scitotenv.2019.02.094

Strauss, S. Y., Lau, J. A., \& Carroll, S. P. (2006). Evolutionary responses of natives to introduced species: What do introductions tell us about natural communities? Ecology Letters, 9, 357-374. https://doi. org/10.1111/j.1461-0248.2005.00874.x
Strayer, D. L. (2006). Challenges for freshwater invertebrate conservation. Journal of the North American Benthological Society, 25 , 271-287.

Strayer, D. L., Eviner, V. T., Jeschke, J. M., \& Pace, M. L. (2006). Understanding the long-term effects of species invasions. Trends in Ecology and Evolution, 21, 645-651. https://doi.org/10.1016/j. tree.2006.07.007

Tachet, H., Richoux, P., Bournaud, M., \& Usseglio-Polatera, P. (2010). Invertébrés d'eau douce: Systématique, biologie, écologie. Paris: CNRS éditions.

Thomsen, M. S., Olden, J. D., Wernberg, T., Griffin, J. N., \& Silliman, B. R. (2011). A broad framework to organize and compare ecological invasion impacts. Environmental Research, 111, 899-908. https://doi. org/10.1016/j.envres.2011.05.024

Tickner, D., Opperman, J. J., Abell, R., Acreman, M., Arthington, A. H., Bunn, S. E., ... Young, L. (2020). Bending the curve of global freshwater biodiversity loss: An emergency recovery plan. BioScience, 70, 330-342. https://doi.org/10.1093/biosci/biaa002

Tiegs, S. D., Costello, D. M., Isken, M. W., Woodward, G., Mclntyre, P. B., Gessner, M. O., ... Zwart, J. A. (2019). Global patterns and drivers of ecosystem functioning in rivers and riparian zones. Science Advances, 5, 1-9. https://doi.org/10.1126/sciadv.aav0486

Tolkkinen, M. J., Heino, J., Ahonen, S. H. K., Lehosmaa, K., \& Mykrä, H. (2020). Streams and riparian forests depend on each other: A review with a special focus on microbes. Forest Ecology and Management, 462, 117962. https://doi.org/10.1016/j.foreco.2020.117962

Twardochleb, L. A., Olden, J. D., \& Larson, E. R. (2013). A global metaanalysis of the ecological impacts of nonnative crayfish. Freshwater Science, 32, 1367-1382. https://doi.org/10.1899/12-203.1

Verberk, W. C. E. P., Siepel, H., \& Esselink, H. (2008). Life-history strategies in freshwater macroinvertebrates. Freshwater Biology, 53, 1722-1738. https://doi.org/10.1111/j.1365-2427.2008.02035.x

Vilà, M., Basnou, C., Gollasch, S., Josefsson, M., Pergl, J., \& Scalera, R. (2009). One hundred of the most invasive alien species in Europe. In Handbook of alien species in Europe (pp. 265-268). Berlin: Springer.

Villéger, S., Mason, N. W. H., \& Mouillot, D. (2008). New multidimensional functional diversity indices for a multifaceted framework in functional ecology. Ecology, 89, 2290-2301. https://doi. org/10.1890/07-1206.1

Warren, R. J., Bahn, V., \& Bradford, M. A. (2012). The interaction between propagule pressure, habitat suitability and density-dependent reproduction in species invasion. Oikos, 121, 874-881. https://doi. org/10.1111/j.1600-0706.2011.20174.x

Wong, M. K. L., Guénard, B., \& Lewis, O. T. (2019). The cryptic impacts of invasion: Functional homogenization of tropical ant communities by invasive fire ants. Oikos, 129, 585-597.

Woodward, G. (2009). Biodiversity, ecosystem functioning and food webs in fresh waters: Assembling the jigsaw puzzle. Freshwater Biology, 54 2171-2187. https://doi.org/10.1111/j.1365-2427.2008.02081.x

Wootton, K. L. (2017). Omnivory and stability in freshwater habitats: Does theory match reality? Freshwater Biology, 62, 821-832. https://doi.org/10.1111/fwb.12908

Yokomizo, H., Possingham, H. P., Thomas, M. B., \& Buckley, Y. M. (2009). Managing the impact of invasive species: The value of knowing the density-impact curve. Ecological Applications, 19, 376-386. https:// doi.org/10.1890/08-0442.1

Zuur, A. F., \& leno, E. N. (2016). A protocol for conducting and presenting results of regression-type analyses. Methods in Ecology and Evolution, 7, 636-645. https://doi.org/10.1111/2041-210X.12577

Zuur, A. F., leno, E. N., Walker, N. J., Saveliev, A. A., \& Smith, G. M. (2009). Mixed effects modelling for nested data. In Mixed effects models and extensions in ecology with $R$ (pp. 101-142). New York: Springer.

Zwerschke, N., Eagling, L., Roberts, D., \& O'Connor, N. (2020). Can an invasive species compensate for the loss of a declining native species? 
Functional similarity of native and introduced oysters. Marine Environmental Research, 153, 104793. https://doi.org/10.1016/j. marenvres.2019.104793

\section{SUPPORTING INFORMATION}

Additional supporting information may be found in the online version of the article at the publisher's website.
How to cite this article: Carvalho, F., Pascoal, C., Cássio, F., Teixeira, A., \& Sousa, R. (2022). Combined per-capita and abundance effects of an invasive species on native invertebrate diversity and a key ecosystem process. Freshwater Biology, 00, 1-14. https://doi.org/10.1111/ fwb.13884 